\title{
Correlation Analysis Between the Health System and Human Development Level Within the European Union
}

\author{
OPREANA Alin, MIHAIU Diana Marieta
}

\begin{abstract}
This study aims to test the correlation between the effects, effort and efficiency of health expenditure in the European Union and Human Development Index (HDI). Although we observe a correlation between HDI, effects and effort in the health system, however, HDI is not correlated with the health system efficiency calculated as the ratio between effect and effort. This aspect shows that the elasticity of the effects of health system reported on the financial allocation (effort of the health system which is expressed as a percentage of GDP) decreases, as the increase of financial allocation in GDP.
\end{abstract}

Index Terms - correlation, effects, effort, health expenditure, Human Development Index.

\section{INTRODUCTION}

Public health is an area of great interest at the EU level, but also at a global level, and that's why we tried to quantify the efficiency of health expenditures among the EU Member States and now it will be considered the intensity of correlation with the HDI. We chose a correlation with the HDI because it is a representative index of the analyzed domain; it measures the average achievements in a country in three basic dimensions of human development: a long and healthy life, access to knowledge and a decent standard of living [7]; logically there should be a close correlation between HD index values and the efficiency of health expenditure.

The HDI is the geometric mean of normalized indices measuring achievements in each dimension. Human Development Index has three dimensions and four indicators, as it can be seen in the table below. The education component of the HDI is measured by mean of years of schooling for adults aged 25 years and expected years of schooling for children of school going age. The health dimension of the index is measured by life expectancy at birth. The decent standard of living component is measured by GNI per capita (PPP US\$)

TABLE 1: THE COMPONENTS OF HUMAN DEVELOPMENT INDEX

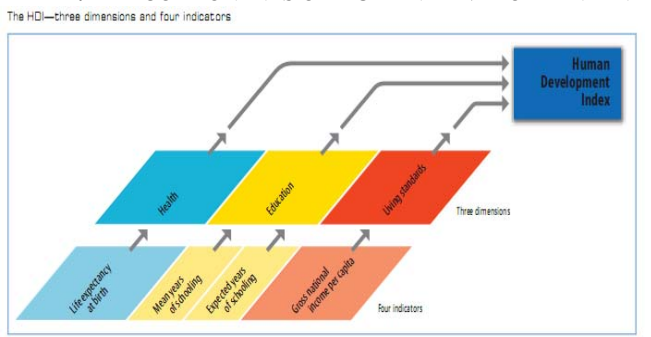

Source: Human Development Report 2010, 20th Anniversary Edition, The Real Wealth of Nations: Pathways to Human Development, Communications Development Incorporated, Washington D.C., Published for the United Nations Development Programme, page. 13.
The values of HDI for European Union member states are presented below, in table 2:

It can be seen that the average value of HDI for EU 27 zone is 0.845 ; the highest values are registered by Ireland, Netherlands, Sweden, Germany, and the smallest one are obtained by Bulgaria and Romania. Regarding the values of "life expectancy at birth" indicator, which is seen as a dimension of nation's health, scoring the lowest values are Lithuania and Romania.

Regarding the second topic, the efficiency of health expenditures among the EU Member States, this is examined by the ratio of the obtained effects and the economic effort expended. In general, an efficiency analysis involves a relationship between efforts (inputs) and effects (outputs), and from a mathematical point of view it can be calculated as the ratio between the amount of effects and amount of efforts (in this case, a value of the ratio higher than lindicates a higher efficiency), or vice versa, the ratio between the amount of effort and the amount of effects (in this case, a lower ratio indicates a higher efficiency) [4]. To achieve an efficiency analysis of health expenditures at the European Union level by benchmarking, representative indicators were elected in order to quantify the amount of effort and the effects shown in the figure 1.

The effort will be represented by total health spending financed from both public and private, as in health care in some countries, financing from private sources reached significant levels. The study of the efficiency of strict public health expenditures would have had poor representation since the effects cannot be separately identified, and would have distorted the results: efficiency of public health expenditures would be higher in countries where private funding was significantly greater, but because of the effects created by the private, and not the public sector.

Given that the indicators presented in figure 1, are expressed in different units of measurement, standardization of data has become a necessary process. The results of the standardization process and the quantification of the effects of effort for EU countries are presented in the table below:

At the EU level, for health is allocated on average 8.04\% of member states' GDP. These funds come at a rate of about $74 \%$ from public resources. However, variations from the average level are large. While France allocates $11 \%$ of GDP, Germany $10.4 \%$ Austria $10.1 \%$, exceeding the EU average, at the other extreme is Romania with $4.7 \%$ of GDP and Estonia with $5.5 \%$. In most countries, most of the funds are public funds, and at the top of the list is still France, because of the $11 \%$ of GDP assigned for health financing, $8.69 \%$ of GDP, i.e. $80 \%$ of the total funding comes from the government's budget; in Denmark $85 \%$ of funds are public, 
$77 \%$ in Germany, $76 \%$ in Austria, $74 \%$ in Belgium, $75 \%$ in Finland, 90\% in Luxembourg. In Bulgaria, however, only $57 \%$ of total health funding comes from public sources, whereas in Cyprus $45 \%$ and in Greece 60\%. Usually, the developed countries are those which provide a broader funding from the public budget of social spending in order to ensure equity in the provision of public services and unhindered access to certain socially disadvantaged categories, but they also offer alternatives through the existence of private services to people with a certain financial comfort.

The situation of funding the health sector in Romania is critical. Romania allocates the lowest percentage of GDP to health, only $4.7 \%$ of which $80 \%$ come from the state budget and national health insurance budget. The low percentage of GDP to health and the high public contribution highlights the underdeveloped private health insurance that could appeal to people with high incomes. The critical situation of health financing appears more prominent in the analysis of health expenditure per capita; in 2008 this level was of 353 Euros per capita in Romania, a very low level by comparison to Belgium's level of 3000 Euros per capita, while Denmark allocates 4000 Euros per capita, Germany and France over 3,000 Euros per capita, but also by comparison to other countries of a similar degree of economic development, such as Hungary which allocates 744 Euros per capita and Poland with 660 euro per capita.

The chart below presents a ranking of the EU countries, based on their total achieved effects in health. The total value of the effects is given by the standardize value of the 11 th indicators analyzed.

Chart no. 1: Ranking of the EU countries according to the obtained effects in health

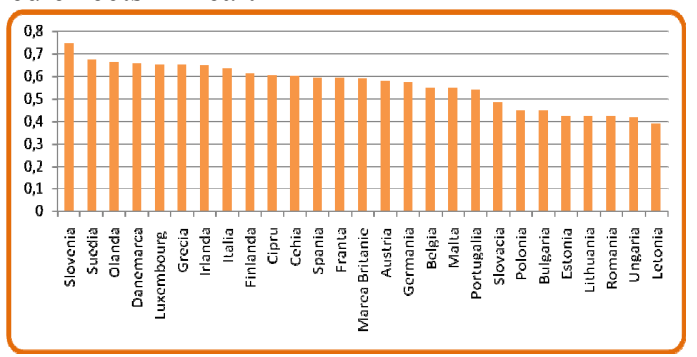

The country which recorded the best results is Slovenia, followed by Sweden, Holland, Denmark and Luxembourg, and the countries with the lowest results were Romania, Hungary and Latvia.

It can be seen that the average efficiency of health spending at the EU level is lower than 1, revealing that the level of benefits is lower than the level of funding. Countries that have achieved success rates, i.e. with a ratio effect / effort greater than 1, are Slovenia and Luxembourg.

France, while ensuring the highest level of funding, seems to be experiencing some problems in the system because it fails to use them effectively, and, as a consequence, the results are slightly above average. A similar situation, as the one in France, can be observed in Germany, Portugal, Belgium and Austria.

Romania, although not reaching the level of efficiency, has an almost balanced ratio between the effects and the efforts that can somehow be interpreted in a favorable way, meaning that the few sources, allocated to health, have been used judiciously. Indeed, Romania occupies the last place in the EU in terms of health results and health financing.

Austria, for example, is 3rd runner-up in terms of funding, after France and Germany, and only on 15th place in terms of benefits yielded by those funds. This suggests that most of the countries that recorded above-average expenditure and below-average results, such as Austria, Belgium, Germany, Greece, Portugal, have significant potential to reduce healthcare spending without affecting the results. As a general conclusion regarding the entire EU, health expenditure is too high compared to the achieved results; in other words, the effects are too low in relation to the effort.

\section{ANALYSIS OF THE RELATIONSHIP BETWEEN THE EFFECTS OF THE HEALTH SYSTEM - HEALTH SYSTEM'S EFFORT - HUMAN DEVELOPMENT INDEX}

This analysis will test the bond strength of the effects of the health system, the effort involved and the value of Human Development Index, according to the following diagram:
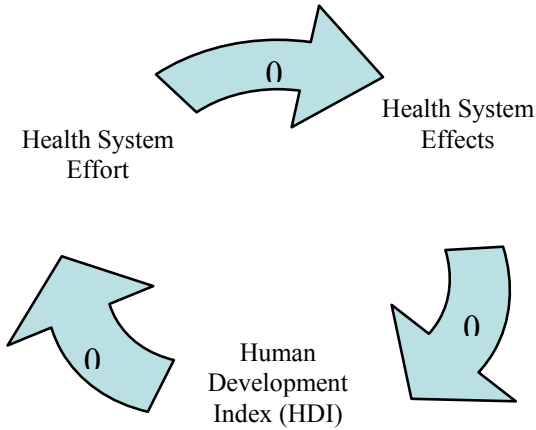

Figure no.2: The correlation between health system effects, effort and Human Development Index

After processing the data, the following values were obtained, in terms of correlation analysis of the three indicators, centralized in the following table:

TABLE NO.4: THE CORRELATION ANALYSIS BETWEEN THE EFFECT, EFFORT OF HEALTH SYSTEM IN EUROPEAN UNION AND HDI

Covariance Analysis: Ordinary

Sample: 127

Included observations: 27

\begin{tabular}{|c|c|c|c|}
\hline \hline Correlation & EFFECTS & EFFORT & HDI \\
\hline EFFECTS & 1.000000 & & \\
\hline EFFORT & 0.555508 & 1.000000 & \\
\hline HDI & 0.745103 & 0.596866 & 1.000000 \\
\hline
\end{tabular}

In the conducted analysis, a special item is the intensity of the relationship between HDI and health system efficiency. This analysis is accomplished with the aid of the correlation indicator and is presented in table number 5, below:

TABLE NO.5: THE CORRELATION BETWEEN HDI AND HEALTH SYSTEM EFFICIENCY IN EU

\begin{tabular}{|c|c|c|}
\hline $\begin{array}{l}\text { Covariance Analysis: } \\
\text { Sample: } 127 \\
\text { Included observations }\end{array}$ & & \\
\hline Correlation & EFFICIENCY & HDI \\
\hline $\begin{array}{c}\text { EFFICIENCY } \\
\text { HDI }\end{array}$ & $\begin{array}{l}1.000000 \\
0.045928\end{array}$ & 1.000000 \\
\hline
\end{tabular}


Although we observe a correlation between HDI, effects and effort in the health system, however, HDI is not correlated with the health system efficiency calculated as the ratio between effect and effort. This aspect shows that the elasticity of effects reported on the financial allocation (effort of the health system is expressed as a percentage of GDP) decreases, as the increase of financial allocation in GDP.

The following charts present the clusters obtained at the EU level based on the established relationships between the health system effects - the involved effort - the Human Development Index.

Chart no.2: The relationship between effects - effort of health system by country, in EU

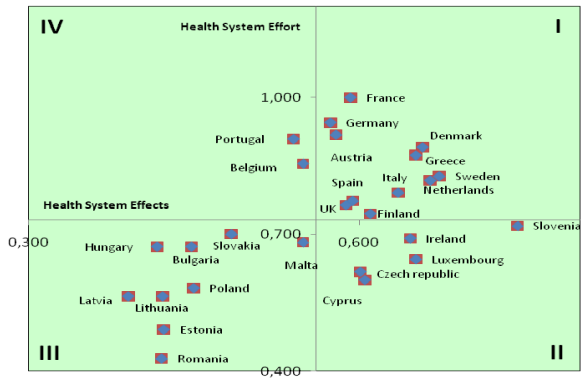

In chart no. 2 we have the following four quadrants corresponding to the identified clusters:

Quadrant I - Countries with high efficiency of the health system financial effort

Quadrant II - Countries with very high efficiency of the health system financial effort

Quadrant III - Countries with decreased effects caused by reduced effort of the health system

Quadrant IV - Countries with reduced effects determined, however, by high efforts regarding the health system

Chart no.3: The relation between effects of health system HDI, by country, in EU

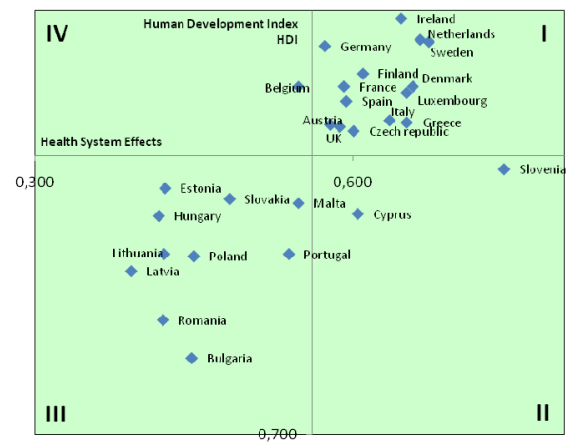

Chart no. 3 shows the close relationship between the effects of health system and the Human Development Index. Thus, in chart no. 3, four quadrants corresponding to four clusters are presented:

Quadrant I - Countries with high health system effects and high HDI

Quadrant II - Countries with high health system effects and low HDI

Quadrant III - Countries with below-average effects of the health system and low HDI

Quadrant IV - Countries with reduced health care system effects and high HDI

Chart no. 4: The relationship between effort of health system - HDI, by country, in EU

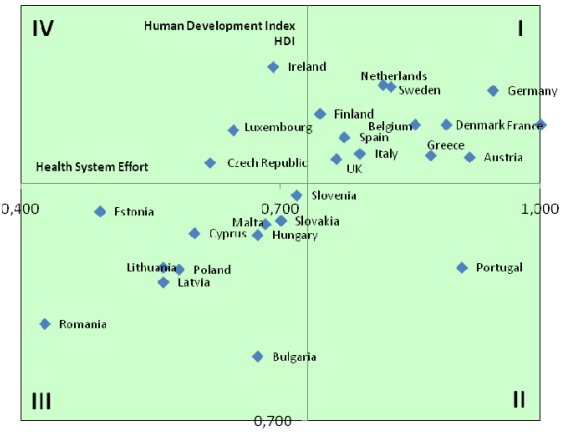

In chart no. 4 we have the following four quadrants corresponding to the identified clusters:

Quadrant I - Countries with high health system effort and high HDI

Quadrant II - Countries with high health system effort and low HDI

Quadrant III - Countries with below-average effort of the health system and low HDI

Quadrant IV - Countries with below-average effort of the health system and high HDI

From the conducted analysis and the results presented above, three broad categories of countries have been identified:

- A total of 11 countries (i.e. $40.74 \%$ of all EU member states) have high effort, high effect, which further leads to a higher HDI: Austria, Denmark, Finland, France, Germany, Greece, Italy, Netherlands, Spain, Sweden, and United Kingdom. As observed, this category includes the Nordic states, which have a health system performance, but also countries that have a high financial allocation relative to GDP, which, however, are strongly affected by these budget efforts in the current period.

- 9 countries (i.e. $33.33 \%$ of all EU member states) have a reduced effort, low effects, which further leads to a lower HDI: Bulgaria, Estonia, Hungary, Latvia, Lithuania, Malta, Poland, Romania, and Slovakia. All these states are part of the new wave of countries that have joined EU and have not yet managed to harmonize their health policies to a management system based on performance.

- 7 countries (i.e. $25.93 \%$ of all EU member states) do not present a direct relationship between the three aspects studied, and these countries are: Belgium, Cyprus, Czech Republic, Ireland, Luxembourg, Portugal, and Slovenia. These states represent a special category because, due to their existing policies, they are registering an increasing and balanced trend through a process of correlating the financial effort with the health system effects, with the final purpose of raising human development (using the quantified HDI).

The result of the correlation indicator of the health system effects and the effort shows the existence of a direct correlation of the two indicators, at the European Union level. This reveals that the EU states that have a higher financial allocation for health care, also register higher and positive results in the health system. It is also apparent from the correlation analysis presented in the table above that there is a strong positive correlation between HDI and the indicator that expresses the effects of the health system. Thus, one can 
state that the level of human development in the EU is directly proportional to the results of the health system.

\section{ACKNOWLEDGEMENT}

Research made under project POSDRU/88/1.5/S/60370 co-funded by European Social Fund through the Sectoral Operational Programme -Human Resources Development 2007-2013".

\section{REFERENCES}

[1] António Afonso, Miguel St. Aubyn, "Non-parametric approaches to education and health efficiency in OECD countries," in Journal of Applied Economics, Universidad del CEMA, 2005, vol. 0, pages 227-246.

[2] António Afonso, Miguel St. Aubyn, "Relative Efficiency of Health Provision: a DEA Approach with Non-discretionary Inputs," Working Papers 2006/33, Department of Economics at the School of Economics and Management (ISEG), Technical University of Lisbon, 2006.
[3] E. Jafarov, V. Gunnarson, "Government Spending On Health Care and Education in Croatia: Efficiency and Reform Options" in International Monetary Fund WP/08/126, 2008, pp.34

[4] Mihaiu, Diana Marieta \& Opreana, Alin \& Cristescu, Marian Pompiliu, 2010. "Efficiency, Effectiveness and Performance of the Public Sector," Journal for Economic Forecasting, Institute for Economic Forecasting, vol. 0(4), pages 132-147.

[5] Opreana Alin, Mihaiu Diana Marieta, "Determining the efficiency of health expenditure as a prerequisite for achieving economic equilibrium in the European Union", manuscript accepted for presentation at International Conference on Economics and Finance Research - ICEFR 2011, Singapore.

[6] Human Development Report 2010, 20th Anniversary Edition, The Real Wealth of Nations: Pathways to Human Development, Communications Development Incorporated, Washington D.C., Published for the United Nations Development Programme, page. 13.

[7] http://hdr.undp.org/en/statistics/indices/

***, http://data.worldbank.org/

***, http://www.un.org/en/databases/\#stats

[8] ***,http://epp.eurostat.ec.europa.eu/portal/page/portal/eurostat/home/ ***, ,World Health Statistics 2009”, World Health Organization ***, "Europe in figures - Eurostat yearbook 2010", Eurostat Statistical Books, pp. 205-242. 